\title{
Editorial: The ethical and social challenges of Construction 4.0
}

Fred Sherratt PhD, MCIOB, C.BuildE, MCABE, AMICE, FHEA

Interim Deputy Dean for Research and Innovation, Faculty of Science and

Engineering, ARU, Chelmsford, UK

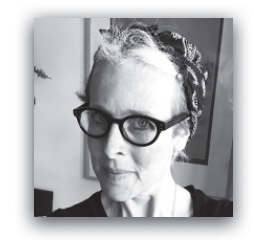

When this themed issue of Proceedings of the Institution of Civil Engineers - Management, Procurement and Law was conceived in 2019, Construction 4.0 was already going to save our industry from the endemic problems of low productivity, weak predictability and poor quality. It promised to transform how we design, engineer, plan, construct and maintain our built environments and infrastructure assets, and all for the better. Yet despite such assertions, Construction 4.0 is still very much a work in progress, comprising a fragmented collection of technologies that range from the use of drones for site surveillance to the development of sophisticated platforms and digital twins with embedded artificial intelligence (AI) and machine learning (ML) for megaproject planning and control. But in spite of this lack of coherence, and perhaps more pertinently a lack of evidence that Construction 4.0 can and will deliver on the grand promises initially made, the quest for this technological revolution has accelerated. Construction 4.0 is now even more vocally championed as vital for post-Covid-19 pandemic recovery. Many recent publications, conferences, webinars and even UK government policies and research agendas make such calls. It is now positioned as our best (if not our only) hope for the future, and so we as academics and professionals must seek to catalyse Construction 4.0 if we are to save our industry.

The initial aim of this themed issue was to provide a critical contribution to challenge and balance the technocratic optimism that already surrounded the Construction 4.0 revolution in 2019. It sought to raise questions around the ethical and social challenges such change will also inevitably bring, as new technologies collide with our social worlds. Fundamentally, technology is not neutral. It has an autonomy and amorality that in combination are potentially dangerous. There are also different agendas in this space that should be acknowledged, not least of those with vested interests in the potential profits to be made. Technological innovations are never without consequence, and Construction 4.0 is already beginning to change the shape of our workforce and how we carry out our work. But just because we can, doesn't mean we should. And certainly not without deliberation, due thought and care. The questions raised around the ethical and social challenges of Construction 4.0 within this themed issue remain as valid now as when they were first posed, and indeed given the desire to 'speed things up', the ability to generate considered and meaningful answers has now become ever more critical.

In this issue, workers and work feature strongly. Sherratt et al. (2020) draw on Ellul's theory of technology and technique to unpack the potential consequences of Construction 4.0 for our industry's workers - both trade and professional. They explore the autonomy currently gifted to the increasing use of technology, and the shifts in work tasks, roles and thus power within this process and for whom this brings most benefit. Barrett (2020) unpacks Construction 4.0 through a feminist lens, revealing the potential for technology to help close the gender gaps and divides that plague our industry. But this potential is, as yet, unrealised and Barrett reveals that the narratives surrounding Construction 4.0 are themselves already firmly gendered to industry norms, and there is a risk our rushing to revolutionise could actually exacerbate current inequalities and result in a digital dystopia. Calvetti et al. (2020) focus on craft workers, specifically the consequences of Construction 4.0 on their work structures and activities, and the challenges that surround them. The real-time monitoring of workers through various technologies raises a number of ethical and legal issues, which Calvetti et al. consider here from management perspectives. They argue that the workers must be involved in the formation of collective agreements that can accept such surveillance, as without such considerations they warn that Construction 4.0 may be stymied due to neglect of the person in the process.

As the ethical and social consequences of new technologies are themselves still being realised, these are areas in which construction professionals are understandably lacking in knowledge. McAleenan (2020) highlights this in his reflections on the increasing use of $\mathrm{AI}$ as part of the Construction 4.0 revolution, and the relationship people have with such technologies, raising concerns around the unintended consequences and potential for harm that such interactions can bring. The relatively new collision of AI and construction raises ethical challenges our industry has never before had to manage, and we need to acknowledge and understand the moral issues that surround machine ethics and autonomous decision making in order to ensure a socially responsible industry of the future. There are also legal consequences for practice, and the legal framework that currently surrounds the digitisation of construction 
and its subsequent management and control is explored by Winfield (2020), a senior construction lawyer. She provides a critical analysis of the ISO 19650 series, how this impacts legal contractual relations in practice and the consequences for digital information management in the future in our new Construction 4.0 world.

The shape of this brave new world is considered by du Plessis and Sherratt (2020), who focus on the outputs that will emerge from a Construction 4.0 industry, through that now ubiquitous place the 'smart city'. They explore the potential consequences of enhanced technology use within our built environments for those that then work, rest and play therein, through both social and ethical lenses. Smart buildings and infrastructure can certainly bring benefits to those who use them, but there is also the potential for them to create a smart dystopia: a vulnerable, unsustainable and unequal space, from which the poorest in society are excluded. du Plessis and Sherratt urge professionals, those with a role in the design, engineering and production of such spaces, to ensure careful consideration of the ethical and social challenges that come with enhanced technology use and 'smart'. It is the role of professionals both to understand, appreciate and mitigate such concerns in their work, and ensure such considerations are embedded within the decision making processes that result in the design and operation of Construction 4.0 places and spaces.

This themed issue opens with a briefing note from Professor Paul Chan (2020). Prof. Chan argues that we have thus far neglected the social and ethical, and to continue to do so may ultimately result in Construction 4.0 failing to deliver at all. He focuses here on people and processes, rather than technologies, to explore change, noting that without their due consideration this revolution will be inevitably restricted in its agenda. Prof. Chan also raises concerns about the data-driven nature of this revolution and the consequences of that for us as humans, and leaves us with some interesting questions for further reflection.

Such questions, and indeed those raised throughout this themed issue by its collective authorship, aim to challenge our readership. But the authors also offer insights, considerations and enhanced understandings that should surround their answers. This issue speaks to both academics in their research and professionals in their practice, and urges diligence and care in our approaches to Construction 4.0. It provides alternative, more critical perspectives for the evaluation of the myriad technologies that make up this revolution, by explicitly incorporating the social and ethical consequences that could occur should they become part of the way we work. Indeed, it is worthy of note that the desire for even more rapid acceleration of the Construction 4.0 agenda without such caution may well exacerbate the ethical and social challenges contained therein, making this themed issue even more timely and relevant on its publication.

\section{Notice}

This year has seen great disruption to normal life and work due to the Covid-19 pandemic. In April, delivery of printed copies of the journal was halted due to reduced Airmail and delays at Customs. Readers can be reassured that purchased 2020 printed journal issues will be posted to them before Christmas. In January, we will see another change as the journal moves to solely onlineonly format. PDF is now the most common format in which to read the journal, reflecting the preference of institutional libraries and the desktop convenience for readers of finding, receiving and sharing articles in PDF. We expect this trend to continue, with fewer subscribers opting to pay extra for issues to be printed and posted to them. If you are one of our readers who does like to receive a hard copy, these will be available to purchase on a per issue and per volume basis. Prices will be announced in the New Year. Readers who require a printed copy for accessibility reasons should contact journals@ice.org.uk.

\section{REFERENCES}

Barrett J (2020) Choose your future: a feminist perspective on Construction 4.0 as techno-utopia or digital dystopia. Proceedings of the Institution of Civil Engineers - Management, Procurement and Law 173(4): 153-157, https://doi.org/10.1680/jmapl.20.00003.

Calvetti D, Magalhães PNM, Sujan SF, Gonçalves MC and Campos de Sousa HJ (2020) Challenges of upgrading craft workforce into Construction 4.0: framework and agreements. Proceedings of the Institution of Civil Engineers - Management, Procurement and Law 173(4): 158-165, https://doi.org/10.1680/jmapl.20.00004.

Chan PW (2020) Briefing: Industry 4.0 in construction: radical transformation or restricted agenda? Proceedings of the Institution of Civil Engineers - Management, Procurement and Law 173(4): 141-144, https://doi.org/10.1680/jmapl.20.00036.

du Plessis C and Sherratt F (2020) Construction 4.0 and built assets in-use: creating an e-topia or dystopia? Proceedings of the Institution of Civil Engineers - Management, Procurement and Law 173(4): 182-189, https://doi.org/10.1680/jmapl.19.00054.

McAleenan P (2020) Moral responsibility and action in the use of artificial intelligence in construction. Proceedings of the Institution of Civil Engineers - Management, Procurement and Law 173(4): 166-174, https://doi.org/10.1680/jmapl.19.00056.

Sherratt F, Dowsett R and Sherratt S (2020) Construction 4.0 and its potential impact on people working in the construction industry. Proceedings of the Institution of Civil Engineers - Management, Procurement and Law 173(4): 145-152, https://doi.org/10.1680/ jmapl.19.00053.

Winfield M (2020) Construction 4.0 and ISO 19650: a panacea for the digital revolution? Proceedings of the Institution of Civil Engineers Management, Procurement and Law 173(4): 175-181, https://doi. org/10.1680/jmapl.19.00051. 